\title{
SURFACE LAYER PROPERTIES OF LOW-ALLOY HIGH-SPEED STEEL AFTER GRINDING
}

\author{
Jan JAWORSKI*, Tomasz TRZEPIECIŃSKI*
}

${ }^{*}$ Faculty of Mechanical Engineering and Aeronautics, Department of Manufacturing and Production Engineering,
Rzeszow University of Technology, Al. Powstańców Warszawy 12, 35-959 Rzeszów, Poland
${ }^{*}$ Faculty of Mechanical Engineering and Aeronautics, Department of Materials Forming and Processing,
Rzeszow University of Technology, Al. Powstańców Warszawy 12, 35-959 Rzeszów, Poland

ïktmiop@prz.edu.pl, tomtrz@prz.edu.pl

received 19 October 2015, revised 23 November 2016, accepted 28 November 2016

\begin{abstract}
Investigations of the surface layer characteristics of selected kinds of low-alloy high-speed steel after grinding were carried out. They were carried out on the flat-surface grinder with a 95A24K grinding wheel without cooling. The influence of grinding parameters was defined especially for: the quantity of secondary austenite, surface roughness, microhardness and grinding efficiency with a large range of grinding parameters: grinding depth $0.005-0.035 \mathrm{~mm}$, lengthwise feed 2-6 m/min, without a cross-feed on the whole width of the sample. It was found that improvement of grinding properties of low-alloy high-speed steels is possible by efficient selection of their chemical composition. The value of the grinding efficiency is conditioned by grinding forces, whose value has an impact on the grinding temperature. To ensure high quality of the tool surface layer (i.e. a smaller amount of secondary austenite, lack of wheel burn and micro-cracks) in the case of sharpening of tools made of low-alloy high-speed steel, the grinding temperature should be as low as possible.
\end{abstract}

Key words: Grinding, High-Speed Steel, Microhardness, Secondary Austenite, Surface Roughness

\section{INTRODUCTION}

Grinding and sharpening are the final operations in the manufacturing of cutting tools. Under the influence of these operations, in the tool surface layer occur e.g. structural changes, surface stresses, plastic deformations and others (Józwik and Pietras, 2013). These phenomena determine the quality of the tools to a great extent, which mainly depends on the state of the surface layer (Jaworski and Trzepieciński, 2016b; Li and Axinte, 2016; Uhlmann et al., 2016). Grinding is an integral process composed of several simultaneous sub-processes, and chemical additives can affect these sub-processes. The past reports on the effect of physico-chemical parameters of the environment on mechanical properties and grindability of materials were reviewed by ElShall (1984). The degree of the effect of grinding on the properties of high-speed steel depends on such factors as the abrasive, the workpiece, the type and parameters of grinding, coolant, etc. (Ding et al., 2015). For example, increasing the speed of grinding or lengthwise feed leads to grinding burns on the surface layer of the workpiece or tool made of steel with low grindability. The mathematical model relating the heat transfer between the grinding wheel, fluid, and the workpiece is presented by $\mathrm{Gu}$ et al. (2004). Coolant fluids have been used in grinding processes to reduce workpiece temperature and decrease the risk of thermal damage (Tawakoli et al., 2011) In addition, thanks to their lubricant properties fluids serve to enhance process performances (Torrance, 1978).

Many studies have shown that the formation of grinding burns denotes the formation of a clear layer having an austeniticmartensitic microstructure on the hardened steel surface, due to secondary hardening (El-Rakayby and Mills, 2013; Romano et al., 2006; Zhou et al., 2016). This shows that the temperature in the grinding zone exceeds the transition temperature $\mathrm{Fe}_{\alpha}-\mathrm{Fe}_{\gamma}$.
In grinding, the literature generally distinguishes two transient temperatures: a background temperature rise and a local temperature rise (Lefebvre et al., 2012). The background temperature results from the cumulative effect of all local heat sources on the ground surface. The background temperature damages the workpiece subsurface, whilst the temperature flashes and heat generated at the grain/workpiece interface increase the wear rate (Lefebvre et al., 2008; 2012). The grain-workpiece interactions at the local level and the wheel-workpiece interactions at the global level are studied by Hou and Komanduri (2004). The first attempt to correlate actual grinding temperatures with structural metallurgical changes in the workpiece was reported by Littman and Wulf (1955). The heat is primarily carried away to the machined part, because the cross-section and volume of the chip are very small, and the grinding wheel hardly conducts heat. Stresses are formed in the surface layer under the influence of heating and phase transformations. The magnitude of stresses may even exceed the allowable stress of the workpiece, which can lead to the formation of micro-cracks on the surface of the workpiece. Thermal damage is one of the main factors which affects workpiece quality, so it is especially important to understand the underlying factors which affect the grinding temperatures. The use of superabrasive grinding wheels is known to reduce the risk of thermal damage of the workpiece (Rowe et al., 1995). A comprehensive overview of thermal analyses for grinding processes and the effect of grinding temperatures on thermal damage is provided by Malkin and Guo (2007). The changes in the microstructure of the steel as a result of grinding depend on its chemical composition and parameters of the grinding (Abidi et al., 2013; Jaworski and Trzepieciński, 2016b). These changes can be divided into two categories:

- changes related to the establishment of microstructure of secondary hardening with tempering; and 
- changes related to the establishment of microstructure with different degrees of tempering.

On the whole, in the surface layer, one changed zone of secondary hardening or secondary tempering, or several zones can be created i.e. secondary hardening, transient and secondary tempering (Bonek, 2014; Moravcik et al., 2012). During the secondary hardening, a clear outer surface layer consisting of a large amount of austenite, usually $\sim 10-70 \%$, is normally formed. Austenite is formed at high intense heat, is very stable, and hardly decomposes upon cooling. However, the decomposition of highspeed steels occurs from $400-450^{\circ} \mathrm{C}$ during the heating. Walton et al. (2006) found that the effect of the heating rate due to the grinding conditions have a significant influence on the $A 3$ austenitic transition temperature. A review of early works concerned on hardening of alloy steel surfaces by grinding was done by Torrance (1978).

Because all of the mentioned changes in the surface layer when sharpening of tools directly affect the durability of the tools, they can be used to assess the grindability of high-speed steel. Steel grindability can be interpreted as a comprehensive parameter that allows one to characterise the ability of steel to provide the required properties of the surface layer under certain conditions (Urbaniak, 2006). For grindability assessment, a knowledge of the efficiency of the grinding process of a particular grade of steel is also important. The grindability strongly depends on the tendency of grinding wheels to blunt. Therefore, to determine the grindability, first we must examine all the physical processes that occur during the grinding. The characteristics of ground surface layer depend on the depth of microhardness variation, depth of occurrence of structural modifications in the surface layer, micro-cracks forming and surface roughness (Foeckerer et al., 2013; Jaworski and Trzepieciński, 2016a; Oliveira et al., 2009; Weiss et al., 2015; Zhang et al., 2015). The grindability of high speed steel in terms of specific grinding energy versus undeformed chip thickness and maximum temperature rise versus specific material removal rate is presented by Krajnik et al. (2011).

Wear and tear of cutting and grinding tools is one of the most important characteristics that define the accuracy of technological system of parts machining (Arsecularatne et al., 2006; Jaworski et al., 2014; Jaworski et al., 2016). Recognition of the machining properties and defining the tool operational reliability as one of the elements of that system is realised through the help of experimental data about wear and tear of a knife-edge, depending on machining time or path (Kulesza et al., 2012).

Here, the measurements of parameters of the surface layer and grinding efficiency of selected kinds of low-alloy high-speed steel were carried out. The aim of the investigations is to find the effect of grinding depth and lengthwise feed on such grinding parameters as the quantity of secondary austenite, surface roughness, microhardness, and grinding efficiency.

\section{MATERIALS AND METHOD}

The cubicoid samples have dimensions of $6 \times 6 \times 65 \mathrm{~mm}$. The heat treatment was carried out according to the recommendation of suitable standards. The selected physical-mechanical properties of the tested steels are shown in Tab. 1.

The investigations were carried out on the flat-surface grinder with a disk-type grinding wheel 95A24K without cooling. The influence of the grinding parameters was defined especially for: quantity of secondary austenite, roughness of surface, microhard- ness and coefficient of grinding with a large range of grinding parameters: $v_{c}=20 \mathrm{~m} / \mathrm{s}, a_{p}=0.005-0.035 \mathrm{~mm}, v_{f}=2-6 \mathrm{~m} / \mathrm{min}$, without cross-feed on the whole width of sample. After each study, the disk-type grinding wheel was dressed by diamond dresser. The temperature was measured using a half-artificial thermocouple according to methodology, which is known. The force was measured using a dynamometer, whereas the roughness of the surface was measured using Surtronic $3+$ profilograph and the microhardness using the Brivisor KL2 microhardness tester on oblique cuts. The surface roughness is calculated by choosing cut-off length of $0.8 \mathrm{~mm}$, according to the recommendation of ISO 3274:1998 and ISO 4288:1998 standards. The amount of secondary austenite both on the surface and in depth was determined using a Philips device.

\section{RESULTS AND DISCUSSION}

\subsection{Microhardness}

To increase the efficiency of sharpening by means of increasing its parameters, it is better to increase lengthwise feed than the grinding depth. The microhardness of the surface layer in relation to the grinding depth was measured on the skew-polished sections. The microhardness of HS3-1-1 steel has undergone considerable modification together with an increase of grinding depth (Fig. 1). The decrease of microhardness can be observed at $a_{p}=$ $0.015 \mathrm{~mm}$ and increase of microhardness at $a_{p}=0.025-0.035$ $\mathrm{mm}$. The decrease of hardness for HS6-5-2 steel is not observed at all cutting depths and decrease of hardness at $a_{p}=0.035 \mathrm{~mm}$ is less substantial (Fig. 2). Results confirm higher propensity to structural modifications for HS3-1-1 steel during grinding. At the distance from the surface layer $d_{s}=0.02 \mathrm{~mm}$ for both steels the change of microhardness value is not observed.

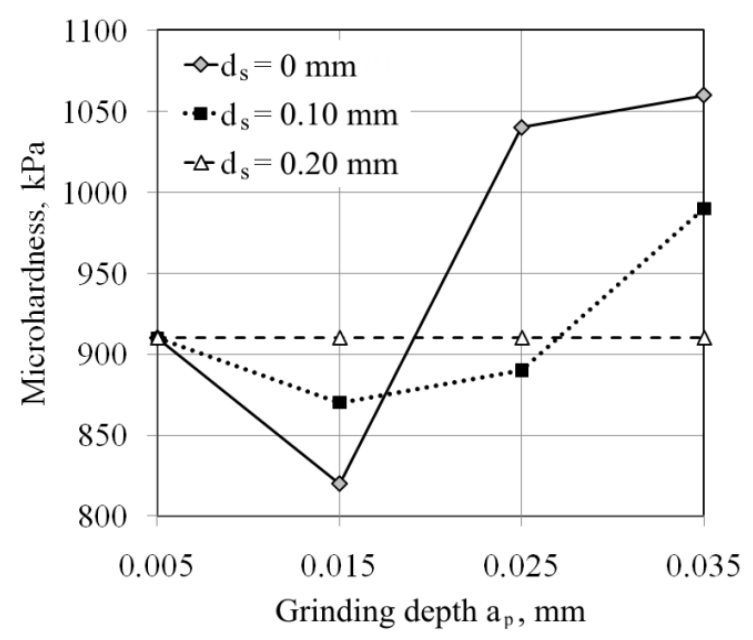

Fig. 1. Effect of grinding depth on microhardness of HS3-1-1 steel

\subsection{Secondary austenite}

In many investigations (e.g., Bonek, 2014; Sinopalnikov and Grigoriew, 2003) the amount of secondary austenite is a main criterion in the evaluation of surface layer quality during tools sharpening. 
Tab. 1. Low-alloy high-speed steel grades - chemical constitution and physical-mechanical properties

\begin{tabular}{|c|c|c|c|c|c|c|c|c|c|c|}
\hline \multirow[b]{2}{*}{ Steel grade } & \multicolumn{6}{|c|}{ Chemical constitution in \% wt. } & \multicolumn{4}{|c|}{ Physical-mechanical properties } \\
\hline & C & W & Mo & $\mathrm{Cr}$ & V & $\mathrm{Si}$ & Hardness HRC & $\begin{array}{c}\text { Bending strength } \\
\mathrm{R}_{\mathrm{g}}, \mathrm{MPa}\end{array}$ & $\begin{array}{c}\text { Impact resistance, } \\
\mathrm{J} / \mathrm{m}^{2}\end{array}$ & $\begin{array}{c}\text { Hardening } \\
\text { temperature, }{ }^{\circ} \mathrm{C}\end{array}$ \\
\hline HS3-3-3 & 1.00 & 2.98 & 2.83 & 4.27 & 2.30 & - & 64 & $3400 \div 3800$ & $3.2 \cdot 10^{5} \div 4 \cdot 10^{5}$ & $1180 \div 1210$ \\
\hline HS2-5-2 & 0.99 & 1.67 & 4.79 & 3.78 & 1.15 & - & 64 & $3000 \div 3400$ & $4 \cdot 10^{5} \div 4.5 \cdot 10^{5}$ & $1080 \div 1170$ \\
\hline HS3-1-1 & 1.11 & 3.35 & 1.15 & 4.65 & 1.75 & 2.05 & $63 \div 68$ & $3000 \div 3600$ & $4.6 \cdot 10^{5}$ & $1080 \div 1170$ \\
\hline HS6-5-2 & 0.82 & 5.55 & 5.13 & 4.27 & 2.06 & - & 64 & $3200 \div 3600$ & $4.8 \cdot 10^{5}$ & $1200 \div 1230$ \\
\hline
\end{tabular}

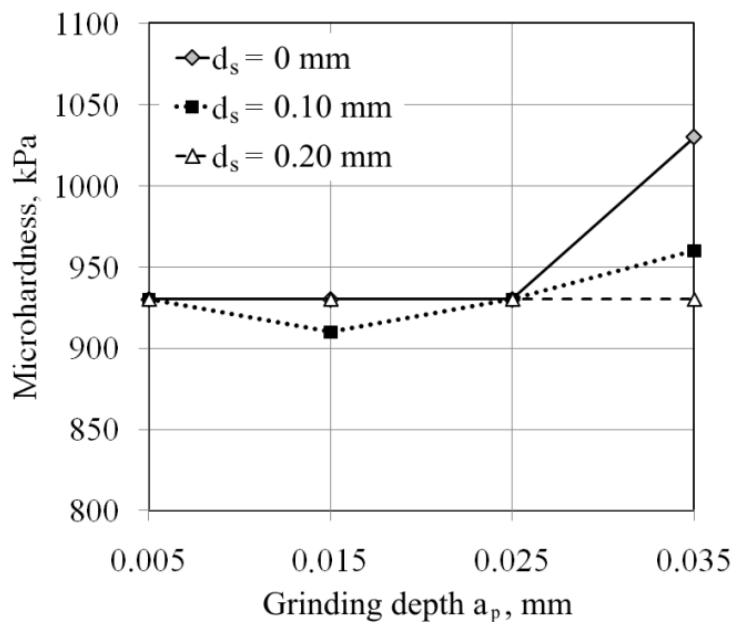

Fig. 2. Effect of grinding depth on microhardness of HS6-5-2 steel

The effect of grinding depth in a range of $0.005-0.035 \mathrm{~mm}$ on the amount of secondary austenite for HS3-1-1 and HS6-5-2 steels is presented in Fig. 3. The amount of secondary austenite for HS3-1-1 steel is larger than for HS6-5-2 steel and increases with increasing grinding depth.

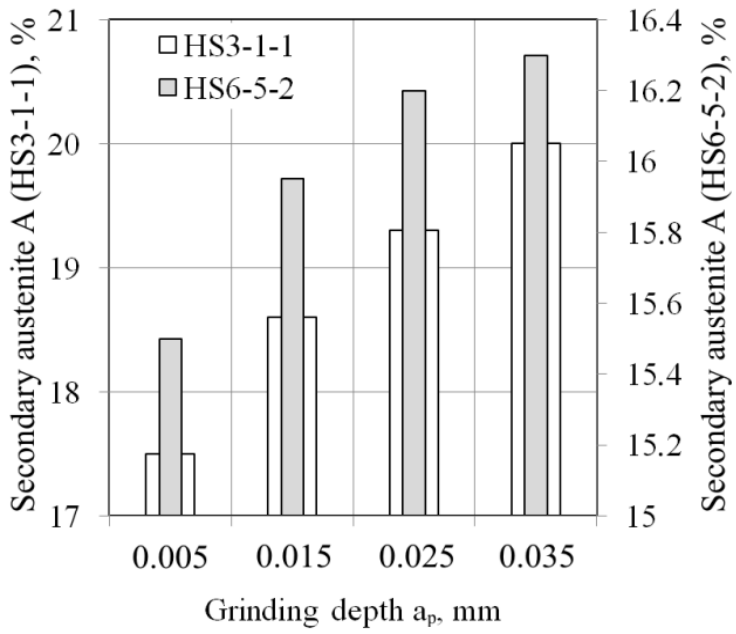

Fig. 3. The influence of grinding depth on the amount of secondary austenite

The influence of lengthwise feed on the amount of secondary austenite for both on the surface layer and at the depth of 0.01 $\mathrm{mm}$ is shown in Fig. 4. The amount of secondary austenite at the depth of $0.01 \mathrm{~mm}$ deceases with increasing lengthwise feed; however at a lengthwise feed $v_{f}=6 \mathrm{~m} / \mathrm{min}$, the amount of austenite is almost imperceptible. With lengthwise feed increase, austen- ite is located in more thin layers, which is proved by decreasing its content at a depth of $0.01 \mathrm{~mm}$, although its amount is considerably higher on the surface layer (Fig. 4). The impact of grinding depth on the amount of austenite on the surface layer is presented more distinctly.

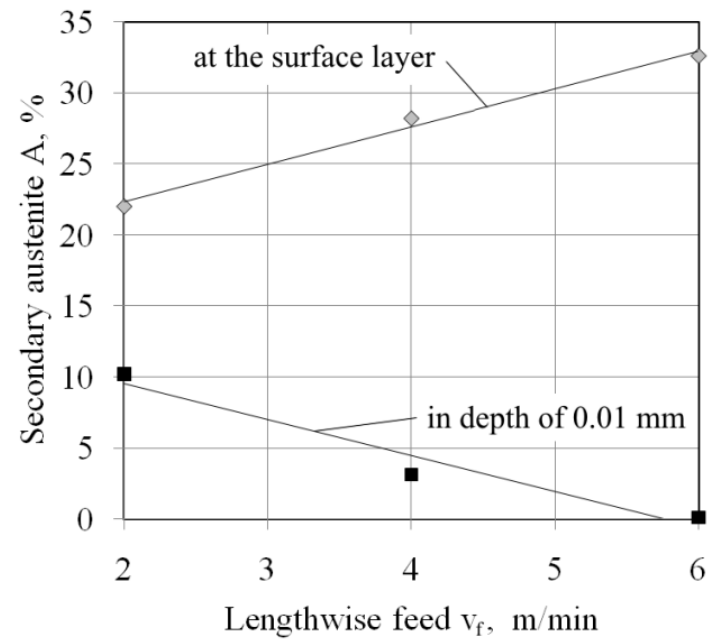

Fig. 4. The influence of lengthwise feed on the amount of secondary austenite for HS6-5-2 high-speed steel

\subsection{Surface roughness}

Results of the measurement of the Ra parameter are presented in Fig. 5 and Tab. 2. Substantial differences of surface finish for selected steel grades are not observed.

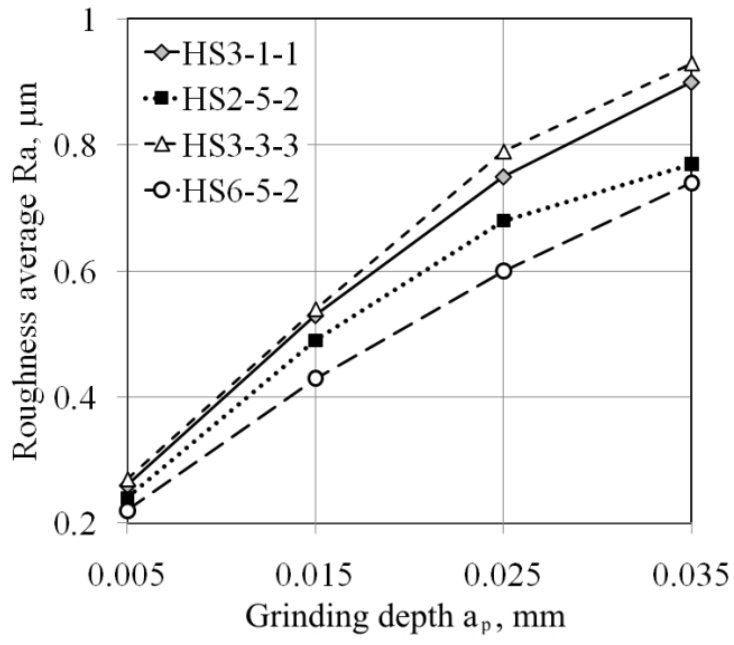

Fig. 5. Effect of grinding depth on the Ra parameter value 
The value of Ra parameter increases together with an increase of grinding depth (Fig. 2) and lengthwise feed (Tab. 2), for all steels used. Furthermore, the quite linear relation between the roughness average $\mathrm{Ra}$ and the grinding depth is observed (Fig. 5). Differences in the surface finish do not have an impact on the machinability of tools.

Tab. 2. Effect of lengthwise feed $\mathrm{v}$ on the roughness of the average Ra value

\begin{tabular}{|c|c|c|}
\hline Steel grade & $\mathbf{V}_{\mathbf{f}}, \mathbf{m} / \mathbf{m i n}$ & $\mathbf{R a}, \boldsymbol{\mu m}$ \\
\hline \multirow{2}{*}{ HS3-1-1 } & 4 & 0.67 \\
\cline { 2 - 3 } & 6 & 0.80 \\
\hline \multirow{2}{*}{ HS3-3-3 } & 4 & 0.63 \\
\cline { 2 - 3 } & 6 & 0.77 \\
\hline \multirow{2}{*}{ HS6-5-2 } & 4 & 0.71 \\
\cline { 2 - 3 } & 6 & 0.86 \\
\hline \multirow{2}{*}{ HS2-5-2 } & 4 & 0.63 \\
\cline { 2 - 3 } & 6 & 0.74 \\
\hline
\end{tabular}

\subsection{Grinding ratio}

The value of grinding efficiency can be, to a certain degree, the characteristic of efficiency and quality of low-alloy high-speed steel grinding process. The value of this parameter is evaluated using (Jaworski, 2002):

$K=Q_{m} / P_{y}$

where: $Q_{m}$ - the amount of material that is removed, $P_{y}$ - inverted grinding force.

The values of grinding efficiency are shown in Fig. 6. Lowalloy high-speed steel has poorer grinding properties than HS6-52 steel, with the exception of HS2-5-2, where that ratio is slightly higher. Other investigations of the grinding efficiency value (Masłow, 1974) have shown that in the case of grinding of HS3-11 steel using a CBN grinding wheel, the grinding efficiency value is 2.5 times greater than in the case of grinding using a corundum grinding wheel. Furthermore, in the case of grinding using the corundum wheel, the value of the grinding efficiency is the same for each grade of low-alloy high-speed steel.

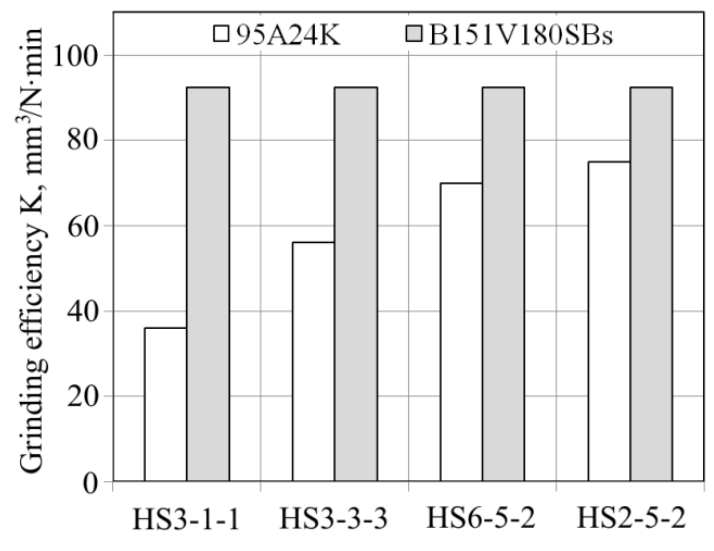

Material

Fig. 6. The grinding efficiency for selected grades of low-alloy high-speed steels during grinding using corundum (B151V180SBs) and CBN (95A24K) wheels at $v_{c}=20 \mathrm{~m} / \mathrm{s}, v_{f}=2 \mathrm{~m} / \mathrm{min}$ and $a_{p}=0.005 \mathrm{~mm}$
Because there is a direct relationship between the grinding temperature and the quality of the surface layer, to improve the grinding efficiency it is necessary to create the conditions allowing us to reduce cutting forces and the temperature in the surface layer of high-speed steel. This can be achieved by using cuttingtool lubricants (Brinksmeier, 1999). However, in industrial conditions, tool sharpening is usually carried out without the use of cutting-tool lubricants and therefore more efficient in this case is the use of cubic boron nitride (CBN) grinding wheels (Sallem and Hamdi, 2015).

\section{CONCLUSIONS}

We have shown that the characteristics of ground surface layer depend on the depth of microhardness variation, the depth of occurrence of structural modifications in the surface layer, and the amount of secondary austenite and process parameters. To ensure a lack of burn and micro-cracks during the sharpening of tools made of low-alloy high-speed steel, the grinding temperature should be maintained as low as possible. To achieve this aim, the following criteria must be met: use of a borazon abrasive disk, decreasing the sharpening parameters, or selection of optimal grinding fluids for the specific conditions. To increase the efficiency of sharpening by means of increasing its parameters, it is better to increase the lengthwise feed than the grinding depth.

\section{REFERENCES}

1. Abidi H., Rezaei S.M., Sarhan A.A.D. (2013), Analitycal modeling of grinding wheel loading phenomena, International Journal of Advanced Manufacturing Technology, 68(1-4), 473-485.

2. Arsecularatne J.A., Zhang L.C., Montross C. (2006), Wear and tool life of tungsten carbide, PCBN and PCD cutting tools, International Journal of Machine Tools and Manufacture, 46(5), 482-491.

3. Bonek M. (2014), The investigation of microstructures and properties of high speed steel HS6-5-2-5 after laser alloying, Archives of Metallurgy and Materials, 59, 1647-1651.

4. Brinksmeier E., Heinzel C., Wittmann M. (1999), Friction, cooling and lubrication in grinding, CIRP Annals - Manufacturing Technology, 48(2), 581-598.

5. Ding Z., Li B., Liang S.Y. (2015), Phase transformations and residual stress of Maraging C250 steel during grinding, Materials Letters, 154, 37-39.

6. El-Rakayby A.M., Mills, B. (2013), On the microstructure and mechanical properties of high-speed steels, Journal of Materials Science, 23(12), 4340-4344.

7. El-Shall H. (1984), Physico-chemical asects of grinding: a review of use of additives, Powder Technology, 38, 275-293.

8. Foeckerer T., Zaeh M.F., Zhang O.B. (2013), A three-dimensional analytical model to predict the thermo-metallurgical effects within the surface layer during grinding and grind-hardening, International Journal of Heat and Mass Transfer, 56(1-2), 223-237.

9. Gu R.J., Shillor M., Barber G.C., Jen T. (2004), Thermal analysis of the grinding process, Mathematical and Computer Modelling, 39(9-10), 991-1003.

10. Hou Z.B., Komanduri R. (2004), On the mechanics of the grining process, Part II-thermal analysis of the fine grinding, International Journal of Machine Tools and Manufacture, 44(2-3), 247-270.

11. Jaworski J., Kluz R., Trzepieciński T. (2014), The influence of machining parameters on the place of formation and intensity of the wear process of drills, Tribologia, 45(3), 81-90 (in Polish). 
12. Jaworski J., Kluz R., Trzepieciński T. (2016), Operational tests of wear dynamics of drills made of low-alloy high-speed HS2-5-1 steel, Eksploatacja i Niezawodnosc - Maintenance and Reliability, 18(2), 271-277.

13. Jaworski J., Trzepieciński T. (2016a), Grindability of selected grades of low-alloy high-speed steel, Advances in Science and Technology Research Journal, 10(31), 222-228.

14. Jaworski J., Trzepieciński T. (2016b), Research on durability of the turning tools made of low-alloy high-speed steels, Kovové Materialy Metallic Materials, 54(1), 17-25.

15. Józwik J., Pietras P. (2013), Investigation and assessment of occupational risk of the metal cutting machine tool stand, Advances in Science and Technology Research Journal, 7(20), 47-54.

16. Krajnik P., Drazumeric R., Badger J., Kopač J., Nicolescu C.M. (2011), Particularities of grinding high speed steel punching tools, Advanced Materials Research, 325, 177-182.

17. Kulesza E., Dąbrowski J.R., Sidun J., Neyman A., Mizera J. (2012), Freeting wear of materials - methodological aspects of research, Acta Mechanica et Automatica, 6(3), 58-61.

18. Lefebvre A., Lanzetta F., Lipinski P., Torrance A.A. (2012), Measurement of grinding temperatures using a foil/workpiece thermocouple, International Journal of Machine Tools and Manufacture, 58, 1-10.

19. Lefebvre A., Lipinski P., Vieville P., Lescalier C. (2008), Experimental analysis of temperature in grinding at the global and local scales, Machining Science and Technology, 12(1), 1-14.

20. Li H.N., Axinte D. (2016), Textured grinding wheels: A review, International Journal of Machine Tools and Manufacture, 109, 8-35.

21. Littman, W. E., Wulff, J. (1955), The influence of the grinding process on the structure of hardened steels, Transactions of the American Society for Metals, 47, 692-714.

22. Malkin S., Guo C. (2007), Thermal analysis of grinding, CIRP Annals - Manufacturing Technology, 56(2), 760-782.

23. Masłow E.N. (1974), Theory of material polishing, Maschinostrojenie, Moscow.

24. Moravcik R., Stefanikova M., Cicka R., Caplovic L., Kocurova K., Sturm R. (2012), Phase transformations in high alloy cold work tool steel, Strojniski Vjesnik - Journal of Mechanical Engineering, 58(12), 709-715.

25. Oliveira J.F.G., Silva E.J., Guo C., Hashimoto F. (2009), Industrial challenges in grinding, CIRP Annals - Manufacturing Technology, 58(2), 663-680.
26. Romano P., Velasco F.J., Torralba J.M., Candela N. (2006), Processing of M2 powder metallurgy high-speed steel by $419(1-2)$, 1-7.

27. Rowe W.B., Black S.C.E., Mills B. (1995), Experimental investigation of heat transfer in grinding, CIRP Annals Manufacturing Technology, 44(1), 329-332.

28. Sallem H., Hamdi H. (2015), Analysis of measured and predicted residual stresses induced by finish cylindrical grinding of high speed steel with CBN wheel, Procedia CIRP, 31, 381-386

29. Sinopalnikow W.A., Grigoriew S.N. (2003), Reliability and diagnosis of technological systems, MGU Stankin, Moscow.

30. Tawakoli T., Hadad M., Sadeghi M.H., Daneshi A., Sadeghi B. (2011), Minimum quantity lubrication in grinding: effects of abrasive and coolant-lubricant, Journal of Cleaner Production, 19(17-18), 2088-2099.

31. Torrance A.A. (1978), Metallurgical effects associated with grinding Proceedings of 19th Machine Tool Design and Research Conference, Manchester, England, 637-644.

32. Uhlmann E., Lypovka P., Hochschild L., Schröer N. (2016), Influence of rail grinding process parameters on rail surface roughness and surface layer hardness, Wear, 366-367, 287-293.

33. Urbaniak M. (2006), Effect of the conditioning of CBN wheels on the technological results of HS6-5-2 steel grinding, Archives of Civil and Mechanical Engineering, 6(2), 31-39.

34. Walton I.M., Stephenson D.J., Baldwin A. (2006), The measurement of grinding temperatures at high specific material removal rates, International Journal of Machine Tools \& Manufacture, 46, 1617-1625

35. Weiss B., Lefebvre A., Sinot O., Marquer M., Tidu A. (2015), Effect of grinding on the sub-surface and surface of electrodeposited chromium and steel substrate, Surface and Coatings Technology, 272, 165-175.

36. Zhang D., Li C., Jia D., Zhang Y., Zhang X. (2015), Specific grinding energy and surface roughness of nanoparticle jet minimum quantity lubrication in grinding, Chinese Journal of Aeronautics, 28(2), 570-581.

37. Zhou N., Peng R.L., Pettersson R. (2016), Surface integrity of 2304 duplex stainless steel after different grinding operations, Journal of Materials Processing Technology, 229, 294-304. 